TABLE VII-Malaria in

Oceania

\begin{tabular}{ll}
\hline & $\begin{array}{c}\text { Risk high; chloroquine } \\
\text { resistance present }\end{array}$ \\
\hline $\begin{array}{l}\text { Regimen } \\
\text { Countries }\end{array}$ & $\begin{array}{l}\text { Mf or MaCq } \\
\text { Papua New Guinea } \\
\text { Solomon Islands } \\
\text { Vanuatu }\end{array}$
\end{tabular}

*See table I. avoid mosquito bites, and carry standby treatment. In Thailand the major tourist cities such a Bangkok, Pattaya, Phuket, and Chiangmai are malaria free. The rural areas around them have a risk of malaria but resistance to all the commonly used prophylactics is common. Under these circumstances where the protective efficacy is so low the recommendation is also to take no chemoprophylaxis but to seek immediate medical advice in the event of a fever. Those travelling extensively overland or to the eastern or western borders of Thailand, where transmission is high, or to Cambodia should seek specialist advice before travelling, as mefloquine resistance is now a considerable problem on the eastern border of Myanmar (Burma), the east and west borders of Thailand, and the western and northern borders of Cambodia.

TABLE IX-Malaria in Latin America

\begin{tabular}{|c|c|c|}
\hline & $\begin{array}{l}\text { Risk variable; } \\
\text { no chloroquine resistance }\end{array}$ & $\begin{array}{l}\text { Risk variable or high; } \\
\text { chloroquine resistance present }\end{array}$ \\
\hline $\begin{array}{l}\text { Regimen } \\
\text { Countries }\end{array}$ & \begin{tabular}{l}
\multicolumn{1}{c}{$\mathrm{Cq}_{\mathrm{q}}$} \\
Argentina (a few areas only) \\
Betize \\
Costa Rica (rural) \\
Dominican Republic \\
El Salvador \\
Guatemala \\
Haiti \\
Honduras \\
Mexico (rural, little visited areas) \\
Nicaragua \\
Paraguay (rural, October to May) \\
Peru (below $1500 \mathrm{~m}$ )
\end{tabular} & $\begin{array}{l}\text { CqP } \\
\text { Bolivia (below } 2500 \mathrm{~m} \text { ) } \\
\text { Brazil (rural, some areas)t } \\
\text { Colombia } \\
\text { Ecuador } \\
\text { French Guiana } \\
\text { Guyana } \\
\text { Panama } \\
\text { Surinam } \\
\text { Venezuela (rural; Caracas and main cities } \\
\text { free of malaria) }\end{array}$ \\
\hline
\end{tabular}

^See table I.

tAmazonia region of Brazil has high risk of chloroquine resistance and mefloquine is recommended for short term travellers (up to three months abroad) without contraindications.

OCEANIA (TABLE VII)

In Papua New Guinea, the Solomon Islands, and Vanuatu transmission of malaria is intense, and in Papua New Guinea multiply drug resistant malaria is a major problem. The advice given here is consistent with that given to the many Australian visitors to those islands.

\section{LATIN AMERICA (TABLE IX)}

In Central America there is a low to moderate risk of malaria without chloroquine resistance (except in south Panama). This is also the case in part of the west of South America. Elsewhere in South America malaria is highly endemic in patches and chloroquine resistance is common. This is especially the case in the Amazonia region.

\section{Appendix}

Contributors to the recommendations are: $\operatorname{Dr} \mathbf{R} H$ Behrens, Professor D J Bradley (chairman), Dr A D M Bryceson, Dr P L Chiodini, Dr P D Clarke, Brigadier G O Cowan, Dr C Dow, Dr J Dunlop, Dr C J Ellis, Professor A Geddes, Professor H M Gilles, M P Golightly, Squadron Leader A D Green, Dr M Janosi, Wing Commander F Jones, Dr G Lea, Dr J Leese, Dr J Levine, Brigadier C J Lewthwaite, Professor K McAdam, Surgeon Commander A R O Miller, Professor G Pasvol, Professor W Peters, Dr T Peto, Dr P PhillipsHoward, Sister F Rayside, Dr J Stewart, Dr R StanwellSmith, Dr E Walker, Professor D A Warrell, Dr W R C Weir, Dr G B Wyatt, Mrs M Blaze, Dr M J Colbourne, Mrs V Smith, Dr B A Southgate, Professor G A T Targett, Dr D A Warhurst, Dr R H Webber.

\title{
Thomas McKeown and Archibald Cochrane: a journey through the diffusion of their ideas
}

\author{
Carlos Alvarez-Dardet, María Teresa Ruiz
}

In the 1970s Thomas McKeown and Archibald $L$ Cochrane were two of the most influential voices in criticising the dominance of medical thinking. A bibliometric study of the citations to McKeown's The Role of Medicine: Dream, Mirage or Nemesis and Cochrane's Effectiveness and Efficiency: Random Reflections on Health Services was performed from the publication of each book until 1988 to study how their ideas have been disseminated. During the study period 430 papers in the Science Citation Index or the Social Sciences Citation Index cited Cochrane's book, 133 cited McKeown's, and 166 cited both. The citations came mainly from original papers published in journals of internal medicine or public health and epidemiology (35\%) and written by authors from the United States or the United Kingdom. Cochrane's book was cited most frequently in medical journals, suggesting a higher degree of penetration of his ideas among medical scientists. Although the dominance of original papers among the citations suggests that these books have been important in stimulating new knowledge, the main problems that McKeown and Cochrane identified-namely, the relatively small impact of clinical medicine on health outcomes and the poor use of scientific methods in clinical practice-are still with us.

The 1970s were dominated by a world crisis in medical thinking and in health service policies. This crisis was produced by accumulative arguments about the relative lack of effectiveness of medical practice and the inappropriateness of medical thinking to deal with health matters. ${ }^{1-3}$ In the years of economic shortage following the rising price of crude oil these criticisms acquired more relevance in challenging health systems mainly orientated towards expensive therapeutic, biological, and technological objectives. Even the World Health Organisation was affected by this wave of criticism and at the end of the 1970 s produced a profound redefinition of objectives in the meeting at Alma Ata which coined the term "health for all."4

Thomas McKeown and Archibald Cochrane were two of the more influential voices in the $1970 \mathrm{~s}$, and both provided theoretical support to the critical side of the debate through their books: The Role of Medicine: Dream, Mirage or Nemesis by McKeown's and Effectiveness and Efficiency: Random Reflections on Health Services by Cochrane. ${ }^{6}$ Their criticisms of the medical establishment were different, and both of them were keen to emphasise the differences. McKeown's more radical hypothesis can be summarised as follows: the erroneous interpretation of the effect of medicine in improving health in the past and, as a result, unrealistic expectations for the future have led to a distorted appreciation of the role of medicine. In Cochrane's reformist view the lack of effectiveness of medical services and the imbalance between financial inputs into health services and outcomes in terms of health status were attributed to the poor use of scientific method in medicine, especially in evaluating therapeutic interventions, and, in particular, the failure to use experimental designs like randomised control trials. 
The implications of their thinking for research policy, professional practice, the management of health services, and public health policy also differed. From McKeown's hypothesis of the small impact of medicine on health gain comes the idea of intersectoral work, largely developed by the World Health Organisation in the late $1970 \mathrm{~s}$ and espoused in the health for all strategy. ${ }^{4}$ His work could be considered to be one of the theoretical bases for the renaissance of public health in Europe under the name of "the new public health" and for the concept of the healthy public policies developed by Nancy Milio in the 1980s. She supplied a framework for analysing the effects on health of public and corporate policies ${ }^{x}$ with practical applications in nutritional policies."

Cochrane's theory has had its echoes in the 1980s in many aspects of medical and public health theory, especially in the development of new methodological tools by epidemiologists and their application to clinical practice. "'

Although both authors made scientific contributions beyond their books, we carried out a bibliometric study to determine how well cited the books have been since their first publication in English because of their importance in contributing to medical and public health theories.

\section{Methods}

We performed a search in the Social Science Citation Index and the Science Citation Index using as key words the book titles The Role of Medicine and Effectiveness and Efficiency. Between them these indexes annually store over 12 million citations from 6000 journals. The information was collected from the year of publication (1972 for Cochrane's book and 1977 for McKeown's) until 1988. From these databases we recorded the paper title, author and journal name, year, and type of publication and country of origin of any paper that cited either or both books.

Since some papers appeared in both databases we classified them into three groups according to whether they appeared in the Social Science Citation Index only, the Science Citation Index only, or both. We then asked two researchers, blind to the study's purpose, to classify the type of journal each article appeared in, using the following categories: medicine, public health and epidemiology, health services administration, and others (including medical specialty journals, mental health journals, and nursing journals). Lack of agreement between the researchers was resolved by discussion or inclusion in the category of non-classifiable.

We analysed the data to obtain frequency distributions for each variable in relation to the citations of McKeown, Cochrane, and both authors. To try to complete the picture of these two authors' influence we asked the original publisher, the Nuffield Provincial Hospital Trust, for data on book sales and translation into other languages.

\section{Results}

During the study period 430 papers cited Cochrane's book, 133 cited McKeown's, and 166 cited both. The figure shows the time distribution of the citations. Cochrane's citations had a peak after publication followed by a clear peak in 1977 and then fell until 1988. McKeown's book had less impact, also the citations had a trimodal distribution, with a peak following publication in 1979-80 with others in 1983 and 1985. The pattern of citing both authors together showed a clear rising trend from 1985 onwards, and by the end of the study period was the most frequent way of citing the books.

Journals included in the Social Science Citation Index

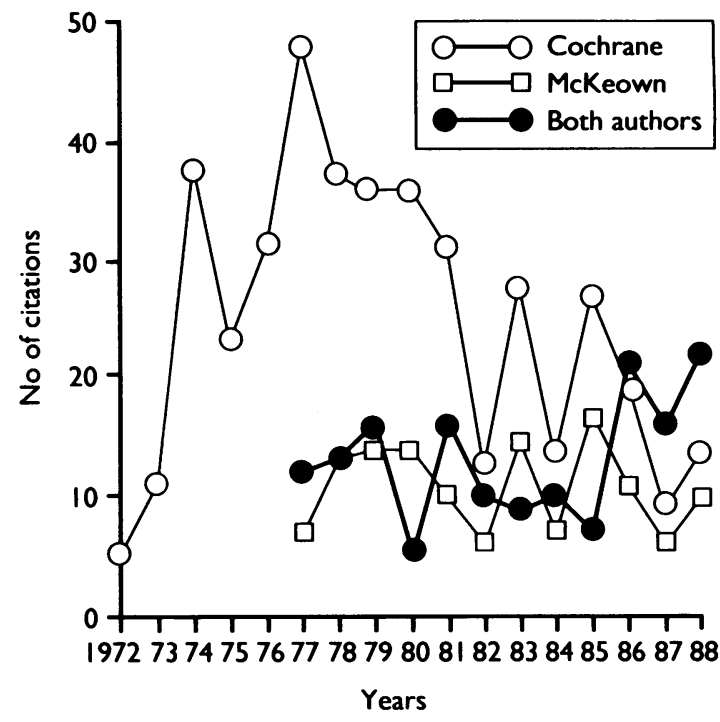

Number of citations each year from publication to 1988

produced $63 \%$ of the citations $(462 / 729 v 163$ in the Science Citation Index and 105 in both). Proportionally McKeown received more citations from the Social Sciences Citation Index (121/133; 91\%) than Cochrane $(298 / 430 ; 69 \%)$, whereas Cochrane received more from the Science Citation Index (78/430; 18\%) than McKeown $(11 / 133 ; 8 \%)$.

The citations came mainly from general internal medicine journals followed by public health and epidemiology journals and health services administration journals (table). McKeown's book received a higher proportion of citations from public health journals $(35 \%)$ than Cochrane's book $(30 \%)$, whereas Cochrane's book received a higher proportion of citations from medical journals ( $46 \%$ ) than McKeown's $(37 \%)$.

Distribution of citations by type of journal and by continent of origin of the citing articles. Results are numbers of citation

\begin{tabular}{lcc}
\hline & Cochrane & McKeown \\
\hline Total No of times cited & 596 & 299 \\
Type of journal: & & \\
Medical & 275 & 111 \\
Public health & 177 & 104 \\
Health service administration & 105 & 46 \\
Others & 30 & 31 \\
Non-classifiable & 9 & 7 \\
Geographical distribution: & 253 & 114 \\
Western Europe & 3 & 2 \\
Easterm Europe & 234 & 125 \\
North America & 1 & 1 \\
South America & 16 & 6 \\
Africa & 6 & 3 \\
Asia & 20 & 13 \\
Oceania & 63 & 35 \\
Unknown & & \\
\hline
\end{tabular}

There was a similar contrast in the geographical distribution of citations. Cochrane received a higher proportion of citations from Western Europe than from North America (42\% v 39\%), whereas McKeown received more from North America than from Western Europe $(42 \% \quad v 38 \%)$ (see table). Overall, Western Europe, especially the United Kingdom and North America accounted for the vast majority of citations.

A large proportion of the citations $(635 / 895 ; 71 \%)$ came from original papers; $13 \%$ (119) came from editorials; 7\% (57) came from reviews; and the remaining citations were from letters to the editors, case reports, or other kind of papers. The distribution of citations among different types of paper showed no differences between the two authors.

The sales figures favoured Cochrane, with 3050 books sold in the period of study, whereas McKeown reached sales of only 1200 . Cochrane also had more 
foreign editions. Effectiveness and Efficiency has been translated into four languages: Polish (Panstvowy Zaklad Wydasnickw Lekarskich), French (Department de l'Economie Publique, Republic et Canton de Geneve), Italian (Giangiacomo Feltinelli Editore, Milan), and Spanish (Salvat Editores, Barcelona). The Role of Medicine has been translated into Italian (Selleri Editore, Palermo) and Spanish (Siglo Ventiuno Editores, México).

\section{Discussion}

As this study shows, the work of Cochrane and McKeown has reached widely within the Western world and continues to be an important source of citations for the international scientific community. Our results probably underestimate the real impact of the books studied, because our bibliometric search was limited to citations to the English editions of the books. This limitation might also explain the geographical distribution of the citations which we found, with a great concentration of citations in English speaking countries. Other important indicators of the diffusion of Cochrane's and McKeown's hypothesis, such as citations in conference proceedings and textbooks, were not examined in this study.

As generally occurs when a new book is published, there were more citations in the early years, but in Cochrane's case there was a second peak, due mainly to citations from the United Kingdom. The synergistic effect of the publication of Prevention and Health. Everybody's Business" and the debate over health policy which surrounded it might explain this.

One important point which arises from examining the pattern of citations is the way Cochrane's and McKeown's ideas have penetrated into the core of knowledge generation-that is, original papers. Although both authors were extensively referenced in editorials and other opinion papers the vast majority of their citations came from papers aimed at communicating new knowledge. This suggests that their work has been important in helping researchers to broaden the scope of the problems they studied.

The differences in the pattern of citations of each author might reflect the acceptability of their theories to different groups of professionals. Cochrane received more citations overall, suggesting that his ideas may have had more impact, especially in medical journals, whereas McKeown received relatively more citations in social science and public health journals. Some confounding might have arisen, however, because McKeown repeated his thesis in later books which we did not examine in our bibliometric search.

McKeown's hypothesis was the more radical in challenging medical thinking and practice, since he challenged directly the dominance of medical thinking and the power of the medical profession. On the other hand, Cochrane's arguments for more scientific input into the practice of medicine could be seen as an attempt to reform medical practice by giving it more scientific credibility. As a result, acceptance of his ideas would have led the medical profession to maintain, or even increase, its power.

Other studies have revisited the question of the role of medicine. ${ }^{12-14}$ Hadley, for example, has produced some empirical evidence using analytical tools applied to mortality and taking into account possible confounding factors. ${ }^{13}$ His study showed that each increase of $10 \%$ in health care expenditure would produce a reduction in mortality of only about $1 \%$.

The major criticisms of McKeown have come not from a challenge to his empirical findings but from criticism of his explanations of historical health gains, especially the importance he gave to the improvement of nutrition. ${ }^{14}$ It now seems reasonable to give more credit than McKeown did to the role of public health measures during the second half of the nineteenth century. These measures combated diseases directly resulting from the insanitary urban environment created by industrialisation. ${ }^{14}$ In fact, the work of public health pioneers in the last century has been put forward as a model for today's public health..$^{15} 16$

The problems that Cochrane and McKeown discussed in their books are still with us. In spite of various attempts to redefine the role of medicine there is general agreement about medicine's relatively poor impact on the health of populations. Even though there have been attempts to reorientate the efforts of Western societies to improve their health towards intersectoral work and a more rigorous evaluation of medical interventions, the current situation is not very different from that in the 1970 s. The health sector is still mainly orientated towards therapeutic interventions, which are often introduced into routine practice without formal evaluation of their efficacy, effectiveness, and efficiency.

There is an apparent paradox between the wide diffusion of the ideas of these two authors and the lack of a wider impact of their ideas on practices and policies. In fact some changes can be seen, such as the formal establishment of national health policies in countries like Finland, ${ }^{17}$ the formation of national agencies for health technology assessment, and the development in recent years of large scale trials in prevention $^{18}$ and treatment. ${ }^{14}$ There is no general theory about how long it takes for ideas to influence practice, and perhaps 15 years is not long enough. Another explanation is related to the relative inefficiency of scientific communication in changing public and private corporate policies. ${ }^{21} \mathrm{~A}$ new institution has been created very recently in Britain, named after Archie Cochrane, in an attempt to reduce the gap between the production of knowledge and its application in practice. ${ }^{21}$

Although questions such as the role of medicine in health gains of the past and how scientific medical practice is are well covered by these two books, two additional questions arise. If the role of medicine was small in the past and nutrition is unlikely to have been entirely responsible for the health gain, what other factors can explain it? And if dissemination in scientific circles of the need to increase the use of scientific methods in medicine is not enough to affect practice how can this change be achieved? These questions, based on the work of Thomas McKeown and Archibald L Cochrane, are perhaps the most important ones facing us as public health doctors or clinicians. Unfortunately McKeown and Cochrane are no longer here to help us in looking for the right answer.

We thank Drs J M Antó and A Segura (Barcelona), X Bosch (Lyon), and J R Ashton (Liverpool) for their comments on previous drafts of this paper, and also to the Nuffield Provincial Hospital Trust for providing the information on sales and editions of the books in languages other than English.

1 Mahler H. Health-A demystification of medical technology. Lancet 1975;ii: 829-33.

2 Illich I. Medical nemesis. Lancet 1974; i:918-21.

3 Kennedy I. The unmasking of medicine. London: Granada Publications, 1985.

4 World Health Organisation. Alma Ata 1977. Primary Health care, WHO, Unicef, Geneva, 1978.

5 McKeown T. The role of medicine: dream, mirage or nemesis. London: Nuffield Provincial Hospital Trust, 1976.

6 Cochrane AL. Effectiveness and efficiency: random reflections on health services. London: Nuffield Provincial Hospital Trust, 1972.

7 Ashton J, Seymour H. The new public health. Milton Keynes: Open University Press, 1988.

8 Milio N. Promoting health through public policy. Philadelphia: FA David Press, $1981: 215-41$.

9 Milio N. Nutrition policy for food rich countries. Baltimore: Johns Hopkins University Press, 1990.

10 Feinstein A. Clinical epidemiology: the architecture of clinical research. Philadelphia: W B Saunders, 1985 
11 Department of Health and Social Security. Prevention and health: everybody's business. A reassessment of public and personal health. London: HMSO, 1976. Starfield $B$. The effectiveness of medical care: validating clinical uisdom. Baltimore: Johns Hopkins University Press, 1985.

3 Hadley J. More medical care, better health? Washington: Urban Institute Press, 1982.

14 Szretzer $S$. The importance of social intervention in Britain's mortality decline c 1850-1914: a re-interpretation of the role of public health. Social History of Medicine 1988;1:1-37.

15 Ashton J. Sanitarian becomes ecologist: the new environmental health. $B M$ 1991;302:189-90.

16 Warren M, Francis $H$. Recalling the medical officer of health. Writings by Sidney Chave. London: King Edward's Hospital Fund for London, 1987.
17 Health for all policy in Finland. WHO Health policy review. World Health Organization Regional Office for Europe. Copenhagen, 1991.

18 Kolata G. Heart study produces a surprise result. Science 1982;218:31-2.

19 Aspirin Myocardial Infarction Study Research Group. A randomized contro trial of aspirin in persons recovered from myocardial infarction. $\mathcal{J} A M A$ trial of aspirin in

20 Milio N. Stirring the social pot. Community effects of program and policy research. Fournal of Nursing Administration 1992;22:24-9.

21 Chalmers I, Dickersin K, Chalmers TC. Getting to grips with Archie Cochrane's agenda. $B M \mathcal{F} 1992 ; 305: 786-8$.

(Accepted 18 February 1993)

\title{
The New NHS: The Second Year
}

\section{East Birmingham: all change}

\author{
Tony Delamothe
}

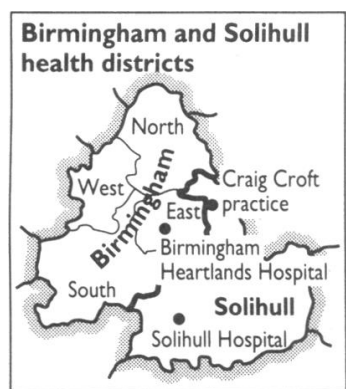

This is the second article in our re-examination of the NHS reforms at the end of their second year
British Medical Journal, London WC1H 9JR Tony Delamothe, deputy editor

BMF 1993;306:1255-8
On my fourth visit to East Birmingham to track the course of the NHS reforms, I expected to find them "bedding down," with little new to report over my visit of a year ago. ${ }^{1-3}$ But I could hardly have been more mistaken. My three contacts within the East Birmingham Health Authority (chief executive, director of corporate management, and director of public health) expected to be out of a job from next April, when East Birmingham was meant to merge with North and West Birmingham Health Authorities. (The region has since put these plans on hold.)

East Birmingham's Yardley Green unit had failed at the eleventh hour in its trust application. Its services for elderly people are moving across the road to the trust hospital; its mental health services are throwing in their lot with providers of similar services in North and West Birmingham Health Authorities and applying for trust status. The community unit is doing the same.

Previously East Birmingham had no fundholders within its boundaries (although outside practices referred patients to its providers). Now, fearful that a newly merged health authority might be out of touch with general practitioners and unhappy about the development of a two tier system of care, nearly 80 general practices from West, North, and East Birmingham had expressed an interest in becoming fundholders as part of a "multifund." And a new regional chairman had been appointed whose enthusiasm for the reforms was already having effects.

\section{Heartlands}

Even East Birmingham Hospital had changed its name-to Birmingham Heartlands Hospital, after a development area some miles down the road. In 1992-3, its first year as a trust, it was expecting to end in balance, having met all its financial targets. According to Robert Naylor, chief executive, the hospital had overperformed its contracts by about $4 \%$ (equivalent to an extra 1500 inpatients). That had brought down most waiting times to less than 12 months compared with many of more than 24 months a year ago.

Last month's closure of the Birmingham General Hospital to general patients was expected to benefit them: the Audit Commission had estimated that about a third of them would come to Heartlands. On the basis of this three new wards (providing 75 beds) will be added to the trust's complement. Naylor had been instrumental in organising a Birmingham-wide deal that money from emergency admissions would be shared out pro rata by local hospitals. "This year we've overperformed all our emergency contracts but have got no extra money for them," said Naylor. "We have said for next year that we will continue to treat patients only if we get paid for them. We want to move to cost and volume contracts across the whole range of services because that means that the risk is shared with the purchaser. With block contracts purchasers have no risk: all of it is held by the provider.

"From April we will be encouraging emergency patients to come here because we will get paid for every additional patient that we treat. In the past we tried to minimise the number of patients we had to treat because we got paid the same amount of money for it. To encourage more patients to come here we will have to review our quality standards and put more effort into providing better quality care. At the end of the day that's what the reforms were about-to provide incentives for people to provide better services, to be more responsive to patients."

At present Naylor was contemplating replacing the line of managerial accountability that ran through managers ("with years of management experience") with one that ran through clinicians ("some of whom have only a few months' experience"). In this American model clinicians would be answerable to a medical director, who would play a much greater part in trust board decisions than the current medical director is allowed to do. "Whichever one we go for will dictate the relative status and roles of all the clinicians involved in management in the hospital," said Naylor. "Having clinicians rather than senior managers making the key decisions is a potentially high risk strategy."

More tangible evidence of structural changes to Heartlands is easy to find. A maternity unit and new operating theatres have opened, and building has begun on a new accident and emergency department. The region had already allocated this money to the hospital before it became a trust, but if the hospital hadn't been granted trust status the capital schemes would have been frozen - as they had been elsewhere in the west Midlands. Building was about to begin on a new day case surgery unit, "something we've wanted to do for years but have never had the capital for."

New outpatient departments for ophthalmology and AIDS and an extension to pathology had either happened or were about to begin. The trust had put up "a strong business case" to replace its back wards: if not funded from the public purse then private funding would be explored. Of five substantial new developments-all of which the hospital had wanted previously-Naylor doubts that any more than two would have been funded under the old arrangements.

Later this year a new renal unit opens. The hospital had entered a competition for "substantial funds" provided by an anonymous donor, and its proposal 